\title{
Wider Worlds of Research for Health Equity: Public Health NGOs as Stakeholders in Open Access Ecosystems
}

\section{Cheryl Holzmeyer}

Sociologist and Visiting Scholar, Department of Environmental Science, Policy, and Management. University of California, Berkeley, CA, USA

Corresponding Author.

This article examines research uses and knowledge stakeholder politics that emerged in an exploratory study of the relevance of open access policies to a spectrum of U.S.-based public health nongovernmental organizations (NGOs). This study demonstrated the clear relevance to public health NGOs of open access to peerreviewed articles, as one form of community informatics. Though not always visible to those oriented toward academic knowledge ecosystems, public health NGOs utilize and conduct a wide range of research, both peer-reviewed and otherwise. Hence, findings indicate that public health NGOs should be more fully recognized, by researchers and policymakers in other contexts, as key stakeholders in knowledge, research, and open access ecosystems. These findings contribute to examination of community information seeking and use in the public health field, with an eye to leveraging community informatics on behalf of health equity.

Holzmeyer. C. (2018). Wider Worlds of Research for Health Equity: Public Health NGOs as Stakeholders in Open Access Ecosystems. The Journal of Community Informatics, 14 (2), 1-16.

Date submitted: 2017-03-31. Date accepted: 2018-08-31.

Copyright (C), 2018 (the author as stated). Licensed under the Creative Commons AttributionNonCommercial-ShareAlike 2.5. Available at: www.ci-journal.net/index.php/ciej/article/view/1379 


\section{Introduction}

This article examines research uses and knowledge stakeholder politics that emerged in an exploratory study of the relevance of open access policies, such as the U.S. National Institutes of Health (NIH)'s Public Access Policy, to staff of a spectrum of U.S.-based public health non-profit, non-governmental organizations (NGOs). Overall, this study demonstrated the clear relevance to public health NGOs of open access to peerreviewed articles, as one form of community informatics. Though not always visible to those oriented toward academic knowledge ecosystems, public health NGOs utilize and conduct a wide range of research, both peer-reviewed and otherwise. Participants' reported uses of peer-reviewed articles ranged from policy advocacy and program management to publications, grant writing, and educational outreach. Hence, findings indicated that public health NGOs should be more fully recognized, by researchers and policymakers in other contexts, as key stakeholders in knowledge, research, and open access ecosystems. These findings contribute to examination of community information seeking and use, which researchers have attended to less often than individuals' information seeking for their personal use (Nkechi and Gurstein 2007).

In addition, this article contends that is it crucial to avoid the reification of Information and Communications Technologies (ICTs) and community informatics initiatives, to broaden the lens of what these may entail. This point goes back to the recognition in the very first issue of this journal that: "Community informatics (CI) - enabling communities with Information and Communications Technologies (ICT) - is a very new development in the academic world, but in reality a very old one in the daily life of communities. It is very new in that only since the arrival of the Internet and low-cost personal computing could those without a direct professional or financial interest begin to engage with and appropriate Information Technology. It is very old, in the sense that information and communications, and using technologies to support these, are as old as communities themselves" (Gurstein 2004). Attuning to this longer history, of the everyday intertwining of communities with myriad communication practices and information technologies that could be conceived of as ICTs, helps to steer clear of reifying ICTs. From this vantage, "community informatics" encompasses not only initiatives to deploy new technologies, but also efforts to include diverse stakeholders in existing knowledge infrastructures - for example, through open access policies. Such a perspective lends itself to an expansive approach to analyzing knowledge ecosystems and their stakeholders, while raising questions about both logistical and discursive inclusion.

\section{Decentering Technologies: "Who is the Community/What is the Community?"}

On that note, environmental and medical sociologist Phil Brown's article, "Who is the Community/What is the Community?" observes that, "Our widespread use of the term 'community' often masks a multiple reality in which there are diverse types of communities, as well as differences within communities" (Brown 2005), while noting, "The history of defining community is long and detailed. One scholar located 94 different definitions, and that was over a half-century ago (Hillery 1955, cited in Patrick 
and Wickizer 1995)." Though the present article does not attempt to delve into all the complexities identified in Brown's article, it acknowledges the need to situate community information seeking and use in social, political, economic, and other relevant contexts. In the case of public health NGOs, it is especially relevant to consider community informatics in the context of social justice movements, particularly those that challenge socio-economic inequalities and structural racism - since these are core social determinants of health that impinge on the work of public health NGOs. In addition, it is fruitful to investigate information seeking and use in communities that span university-based research as well as social movement- and NGO-based "street science" (Corburn 2005; Corburn 2009; Brown et al. 2012), to examine continuities and discontinuities across sectors.

Such contextualization helps to center social institutions and social structures, and decenter information technologies, in community informatics research. This framing builds on longstanding arguments in the field to understand community informatics as a member of the "supporting cast" for community development. As Stoecker writes, "ICT is simply one category of tools for community development, just like housing, small business incubation, family support, and the wide array of other community development tools. As a consequence, Community Informatics becomes part of the supporting cast, not the lead player. In fact, the most important lesson we learned in building the CATNeT [Coalition to Access Technology and Networking in Toledo] community networking project in Toledo was not how to develop small telecenters around the city, but how the process of developing those centers could build relationships among community members" (Stoecker 2005). Such an approach strives toward more reflexive analysis of community informatics and knowledge ecosystems.

Ultimately, situating community informatics, including open access initiatives, in the context of community development enables clearer assessment of how such initiatives fit into broader social problem-solving landscapes, shaped by unequal power relations. As David Eaves underscores in "Building Power Through Data-Sharing," it is crucial to have "a goal for sharing data - and focus on building power" (Eaves 2014). Yet, Eaves notes that one of the most common mistakes he has observed in open data initiatives is that they focus on technology and tools - the how, rather than the why. Questions of power tend to be sidelined within such initiatives, while knowledge and data are foregrounded. Moreover, knowledge and data are too often uncritically equated with power, which in turn is not recognized in its multiple forms (e.g. economic, political, social, and cultural power).

\section{From How to Why: Toward Community Informatics for Health Equity}

As for the "why" of community informatics in the public health field, this paper argues for leveraging community informatics on behalf of health equity - as discussed further in the conclusions. Indeed, this goal is intertwined with recognizing public health NGOs as key stakeholders in knowledge ecosystems. Health equity emphasizes social justice and "attainment of the highest level of health for all people" (Healthy People 2020) as the foundation of a flourishing society, in which all people are valued equally. As the American Public Health Association elaborates, achieving health equity entails that, 
"We optimize the conditions in which people are born, grow, live, work, learn and age. We work with other sectors to address the factors that influence health, including employment, housing, education, health care, public safety and food access. We name racism as a force in determining how these social determinants are distributed" (APHA 2018). Most of all, the rationale for considering community informatics from the vantage of health equity is to examine how public health knowledge ecosystems address - or do not address - the upstream, root causes of core issues, such as poverty and racial residential segregation (Corburn 2009; Bayer and Galea 2015), with which public health NGOs grapple. In sum, health equity provides a touchstone to consider public health knowledge ecosystems' orientation toward health promotion for all - or not.

\section{Methodology}

The findings below are drawn from a larger mixed-methods study of the relevance of open access to publics beyond academia, namely public health NGO staff or physician participants. This study comprised quantitative analysis of web-log data as well as qualitative data from surveys and interviews. The quantitative findings have been published separately, including data on participant awareness of the NIH's Public Access Policy (Moorhead et al. 2015). Here, to attend to participant particularities and broader issues raised, findings from initial and exit surveys of public health NGO staff indicate the range of reported research uses.

The study provided all participants, including 92 staff representatives of 46 public health NGOs, with access to the research resources of Stanford University Library through a study web portal, designed to track quantitative patterns of research access in PubMed over time. The NGOs in this study encompassed a diverse array of organizations, both in their scope as well as the substantive public health issues they addressed. These issues ranged from primary health care access and disease research advocacy to environmental health and homelessness, among other issues. NGOs approached these issues from both downstream (treatment-oriented) and upstream (prevention-oriented) vantages, while working at multiple levels and scales - from NGOs focused on local communities to those oriented toward municipal, regional, state, national, and, occasionally, international scales. Hence, study participants came from both community-based organizations and larger research and advocacy organizations. Of the 65 public health NGO staff that completed online surveys, 47 (72.3\%) reported having previously used PubMed in their work.

Prior to registration to the study web portal, one staff person from each of these 46 NGOs also took part in an initial online survey and an in-depth, semi-structured interview. Organizations were asked to identify the staff member most responsible for research to take part in this portion of the study. Interview participants were also given the option to take part in an orientation to PubMed and strategies for navigating its research resources; 34 participants expressed interest. At the end of the 12-month period during which public health NGO staff could access the study web portal, all 92 staff participants were invited to complete online exit surveys, to report on the usefulness of the study's research access. The data below are from the initial and exit surveys completed by public health NGO participants, conducted between March 2013 and June 
2013 (initial surveys) as well as from March 2014 through July 2014 (exit surveys). Specifically, this article examines survey data on participants' initial self-reported need for access to peer-reviewed research; their formal educational backgrounds; examples of participants' reported uses, if any, of peer-reviewed articles available through the study; as well as participants' reflections on the value of open access and the general impacts of the study's research access on their work. The Stanford Institutional Review Board approved this study and participants consented to participate through the study's web portal.

\section{Summary of Findings}

\section{Inadequate Access to Peer-Reviewed Research in Public Health NGO Field}

An overarching finding of this study was that peer-reviewed articles - and hence, open access policies - are relevant and of potential value to public health NGO staff working to address a range of issues. In the initial survey, public health NGO participants $(\mathrm{N}=$ 46) overwhelmingly reported inadequate access to academic articles, with $74 \%$ describing their access as "poor" or "very poor." Subsequent web-log data further confirmed participants' interest in peer-reviewed research articles, and the general relevance of open access initiatives to public health NGO stakeholders, as reported elsewhere (Moorhead et al. 2015).

\section{Formal Educational Backgrounds of Public Health NGO Staff}

To better understand the range of formal educational backgrounds represented, the study asked participants to report on their postsecondary degrees, if any, when they registered for the study web portal. Their responses are notable for the range of formal educational backgrounds represented, as well as the high representation of graduate degree holders, as summarized below.

Table 1: Public Health NGO Participants' Formal Educational Backgrounds

\begin{tabular}{|l|l|}
\hline Total participants & 92 \\
\hline Participants with a BA or BS degree & $91=99 \%$ of total participants \\
\hline $\begin{array}{l}\text { Participants with at least 1 graduate } \\
\text { degree }\end{array}$ & $73=79 \%$ of total participants \\
\hline Participants with MPH degree & $21=23 \%$ of total participants \\
\hline Participants with PhD or DrPH & $20=20 \%$ of total participants \\
\hline Participants with JD degree & $7=8 \%$ of total participants \\
\hline Participants with MSW degree & $6=7 \%$ of total participants \\
\hline
\end{tabular}

Given that the majority of public health NGO staff participants had completed a B.A. or B.S., as well as some type of graduate degree, study participants comprised a group with considerable formal education. Consequently, the access to peer-reviewed articles 
facilitated by the study could be expected to enable participants to further leverage their formal education and expertise in conducting and evaluating research on behalf of public health. Participants' uses of peer-reviewed articles in their work are discussed in greater detail below.

\section{Uses of Peer-Reviewed Research Articles by Public Health NGO Staff}

In reporting on their uses, if any, of peer-reviewed research articles available through the study, participants in the exit survey $(\mathrm{N}=47)$ mentioned a range of activities and research uses when prompted with the following questions: "In a few sentences, please describe how the research access facilitated by the study Web portal (http:// nihpublic.stanford.edu) affected your work practices over the past year, if at all. (Note: If you did not utilize this access, please describe the reasons or the other research resources that you used instead.)"; and, "Are there articles you accessed through the portal that you found especially useful? If possible, please cite articles and/or groups of articles that you used for specific projects or inquiries. How or why were these articles useful?"

Participants' responses to these questions help to fill in the picture of public health NGO staff research practices and uses of peer-reviewed articles. These practices may be conceptualized as types of community information seeking, use, and knowledge mobilization. They are presented here under categories that emerged through participants' descriptions, with survey quotations illustrating each activity category. They are organized in terms of research practices (literature reviewing, developing models, etc.) as well as organizational knowledge mobilization activities.

These categories help to highlight continuities between NGO-based research practices and university-based research practices, on the one hand, while surfacing research uses and research intermediary roles that may be more particular to the public health NGO field, on the other. Empirically, many of these activities are often intertwined, not mutually exclusive - as reflected by quotations that illustrate multiple activities. Finally, several responses describe how open access to peer-reviewed articles affected the overall dynamics of participants' research practices and knowledge mobilization activities.

\section{Public Health NGO Staff Research Practices}

\section{Literature reviews and meta-reviews}

Public health NGO staff reported using peer-reviewed articles for an array of research activities, including activities that paralleled those of university-based researchers, such as conducting literature reviews and meta-reviews.

- "We were able to conduct literature reviews to assist us in developing a survey on Traumatic Brain Injury, and two Research Annotated Bibliographies." [CH-370]

- "We conducted a meta-review of the peer review and gray literature on healthy food access not long after joining the study." [CH-76] 
Developing models, hypotheses, and research agendas

In addition, participants reported developing models and broader research strategies and agendas, based on their access to peer-reviewed articles.

- "[This past year] I was spending a lot of time on a mathematical model that estimated HIV transmission.... Many of the reference articles were accessed through the web portal." [CH-53]

- "The research access through the study web portal was incredibly valuable in facilitating my work. I used the portal daily and reviewed journal articles...to inform my work and set strategies... An example: I had identified intercellular communication as a research area for funding. I was able to inform our research strategy by reviewing the literature... and identifying specific target areas where the science...could be advanced." [CH-237]

\section{Research and writing of peer-reviewed publications}

Participants drew on peer-reviewed articles, as well, to research and write their own papers for peer-reviewed publication.

- "I would estimate that a few dozen articles that I downloaded through the portal were crucial to either writing articles or answering research questions. I cited many of these in a recent paper published in [an environmental health journal].” [CH-181]

\section{Public Health NGO Knowledge Mobilization Activities}

\section{Grant writing and reporting}

As for NGOs' organizational uses of peer-reviewed articles, various participants mentioned that writing adequate grant proposals and carrying out grant-funded activities often relied on access to peer-reviewed research.

- "Public Access Study was IMMENSELY helpful in helping me craft grant proposals and publications via access to sources that otherwise are out of (easy) reach for our agency (cost, time, etc). The expanded access expedited the entire process and increased the quality/depth of my research." [CH-208]

- "Funders need to be aware of the barriers that applicants might face gathering information. When there are requirements for applications, reports, and published findings, funders need to be aware that many entities (applicants and recipients) don't always have resources needed to complete those requirements. A lack of access to published reports and research is a barrier that many public health entities face, as I suspect your study found." [CH-130] 
- "The research access facilitated by the study was immensely helpful. I work for a research nonprofit, and typically only research staff with a university affiliation have access to paid research databases. I work on a couple NIH grants, and I use online research databases on a daily basis." [CH-422]

\section{Carrying out professional mandates}

More generally, some participants emphasized that their professional responsibilities entailed review of peer-reviewed literature or otherwise deploying research to serve their professional roles and fields.

- "I did not previously have access to research databases through my organization though some of my responsibilities include a review of pertinent literature. Having access to the web portal provided me full text documents of research for my review to enhance the delivery and quality of information included in my work reports." [CH-419]

\section{Program management and development}

Given that many public health NGOs sponsor programs and initiatives, participants reported using peer-reviewed articles in these activities as well.

- "[The study's research access] [a]llowed me to find published ideas to assist with making decisions about programs and initiatives." [CH-130]

\section{Education and outreach activities}

Participants reported using peer-reviewed articles for a range of education and outreach activities, often intertwined with program management and development. These included the creation of web content, printed educational materials, and the identification of speakers for organizational conferences.

- "Being able to access these resources allowed me to spend less time and effort trying to find the information in other ways. I used these resources to find information to create web content and educational materials for my organization." [CH-115]

- "I used the service in spurts. I know there were many other projects I used it for but the ones that come to mind were to finish up a brochure on understanding a lung cancer pathology report, I did massive amounts of research on the effectiveness of support groups for cancer patients (and what facilitators need as well), and also researched information on lung nodules and bronchoscopies in lung cancer." [CH-331]

- "We have used a wide variety of articles during the past year. It would be impossible to cite them. We used articles to identify authors who would be potential speakers for our conferences. We analyzed articles and discussed them 
on our blog. And, we used articles specifically for two lit review projects: one on individual adults experiencing homelessness and one on transitional housing for homeless populations." [CH-314]

\section{Updating expertise and informing advocacy}

Another form of knowledge mobilization reported by participants was the use of peerreviewed articles in advocacy activities. Some participants also emphasized the need to continually update their expertise in specific issue areas.

- "I think the period I used this the most was when I was doing background research for some of the health team's advocacy on [the state's Affordable Care Act program], and recommending that they not use drug retailers as Certified Enrollment Entities. Finding recent research regarding nonprofit hospitals' community benefit was also really useful to some of our other advocacy.” [CH-16]

- "There were several times when I needed access to a protected [i.e. non-open access] document in order to complete my work as an HIV and Hepatitis C advocate and the study access to the printed literature was very helpful." [CH-112]

- "I work in public health (opioid overdose prevention with naloxone) and the PubMed access was invaluable in giving me access to the most up to date articles, which allowed me to keep my public presentation and role as a source of expert advice up to date." [CH-128]

\section{Watchdog activities}

Some NGOs participate in especially contested fields of knowledge and practice, facing off with industrial lobbyists and other commercial interests in their efforts to shape policy and practice. These NGOs may position themselves as public watchdogs of rigorous science and controversies in their fields, using the latest peer-reviewed articles to stay abreast of developments in those fields.

- "The articles that I accessed through the portal were incredibly useful. The most useful way that I used the portal was to access studies referenced in the work that I do. For example, as a watchdog organization, we respond to breaking news related to breast cancer. When a newspaper refers to a study, being able to access the original study to review and use as evidence was invaluable." [CH-51]

\section{Advancing policy work}

Participants also reported using peer-reviewed articles to advance organizational policy work, often overlapping with advocacy on behalf of specific constituencies or with other activities. 
- "I was able to access articles that I cited in a white paper on child-centered health homes I wrote, and generally accessed articles that deepen my understanding of the policy issues I am working on." [CH-414]

\section{Extending public health practice, to address root causes of health inequities}

Finally, this participant noted the possibilities to use peer-reviewed articles to inform rationales to extend public health perspectives to new domains, to address the root causes of health inequities.

- "Most of the work was done in the early phase of access and I do not remember specific articles except for some in: Critical Public Health, Health Promotion International, The International Journal of Health Services, Social Science \& Medicine. I mostly searched for specific articles rather than for references. They were useful in supporting arguments regarding the need for expanding the boundaries of public health practice, with respect to confronting the root causes of health inequity." [CH-184]

\section{Overarching Dynamics of Open Access Research Practices and Uses}

\section{Facilitating positive feedback loops of research and learning}

More generally, these quotations capture the dynamics of increased interest in and uptake of peer-reviewed articles when they are freely available to NGOs, on a par with university-level research access.

- "Loved it. Gave me more access to research. I looked for articles more frequently, knowing I was more likely to be able to read them once I found them. I had better information to inform my policy work." [CH-407]

- "The web access was extremely helpful to my research. As a scientist, I am constantly downloading articles, and often one can lead me to another. Having the ability to instantaneously download articles as needed kept my work moving forward." [CH-457]

\section{Fostering organizational development}

Another participant articulated how such research access, by fostering positive feedback loops of research and learning through multiple domains of NGO activity, can contribute to overall organizational development as well.

- "[Our organization] is not able to gain access to the medical and scientific databases this study made available because it does not have the financial resources necessary. However, access to these databases make it possible for the organization to stay abreast of developments, and more importantly, enable it to get the information needed to support its policy positions, clinical programming, and development work. This access directly facilitated some advances for [the 
organization] over the last year that would not have been possible otherwise. The loss of the access will have a definitive detrimental effect on the organization." [CH-351]

Together, these reported uses of peer-reviewed research articles by public health NGO staff constitute an array of community informatics and organizational knowledge mobilization practices. They indicate ways in which public health NGOs, across diverse constituencies and issues, are crucial research intermediaries, both conducting research and mobilizing research in practice, as discussed further in the article's concluding section.

\section{Participants' Reflections on the Value of Open Access to Their Work}

Lastly, participants completing the exit survey $(\mathrm{N}=47)$ shared reflections on the value of open access, including the potential impacts of the study's research access on their future work, when prompted with the following questions: "Do you think your participation in this study will have any ongoing implications for your work, beyond the study's end? If so, please describe"; and "Any other thoughts, comments or questions about the study or research access that you would like to share?"

\section{Higher expectations, greater commitment to open access}

Some participants noted that the study's research access had significantly raised their expectations and altered their reference points for adequate access to peer-reviewed articles. They also voiced greater interest in and commitment to open access, as an ideal.

- "I feel much more committed to the idea of open access. Before I felt it was important but through this study I felt firsthand how important open access can be (and how frustrating closed access is). Without the open access through the study portal, I have already felt as if I have lost a limb." [CH-51]

- "It will make me more frustrated with my current research access, now that I have tasted the forbidden fruit. :)" [CH-407]

\section{Particular value of open access to non-profits and the public health sector}

Finally, participants noted the particular need for open access and peer-reviewed articles in the non-profit sector, as well as in the public health field, given the perpetual shortage of these sectors' resources relative to the challenges they face.

- "Thanks for doing this study. Access to research is priced so far out of reach for nonprofits. This has been a barrier for some time and really slows down research at institutions without deep pockets." [CH-129]

- "I work with local health departments, and there is an increasing emphasis in our field on using research-based evidence to inform public health practice. Like my non-profit, most LHDs do not have access to many peer-reviewed journals. 
Finding ways to increase access to research results is a critical component in increasing the use of these results in public health practice." [CH-182]

\section{Conclusions and Discussion: Mobilizing a Broader Knowledge Ecology on Behalf of Health Equity}

These study findings indicate the clear relevance of access to peer-reviewed research articles to publics beyond academia, including public health NGO staff, for a wide range of activities on behalf of public health and health equity. Participants' reported research practices and uses of peer-reviewed articles help to fill in the picture of public health NGO community information seeking, use, and knowledge mobilization. They underscore the research capacity of the public health NGO field, including the continuities between NGO-based research practices and university-based research practices (e.g. literature reviewing, developing models, publishing peer-reviewed articles and white papers, etc.). These organizations, working to advance healthier communities and a healthier society for all, should be recognized as key stakeholders in knowledge, research, and open access ecosystems, as both authors and users of the latest peer-reviewed research articles. Open access policies, especially when publicized and oriented toward a wider array of stakeholders (Moorhead et al. 2015), contribute to public health NGOs' community information seeking and "effective use" - i.e., "The[ir] capacity and opportunity to successfully integrate ICTs into the accomplishment of... collaboratively identified goals" (Gurstein 2003). Such goals include communitydefined, grassroots innovations (Gurstein 2013), from organizational programs to policy innovations oriented toward health equity.

This recognition of public health NGOs as valued stakeholders in open access ecosystems is crucial, among other reasons, because these organizations often mobilize research in unique ways that go beyond academic practices and uses. In the process, public health NGOs serve as research intermediaries. As one issue brief on research use to promote children's health articulates, "An intermediary facilitates knowledge exchange and brokers information among stakeholders, providing value-added contributions to decision-making" (Biebel et al. 2013). Another analysis of the use of health research in policy-making observes, "A key barrier to the use of research is the potential users' lack of awareness of a study or body of work and why it may be relevant. Intermediaries...can support better connections between the policy needs of users and findings from researchers" (Gold 2009) - as when public health NGOs mobilize research, whether studies conducted by others or via their own research. Indeed, "Analyzing pathways that link research to its use shows that the world does not divide itself neatly into 'researchers,' who generate knowledge, and 'users,' who apply it" (Gold 2009). This point underscores why it is valuable to investigate information seeking and use in communities that span university-based research as well as social movement- and NGO-based "street science" (Corburn 2005; Corburn 2009; Brown et al. 2012), examining both continuities (literature reviewing, developing models, etc.) and discontinuities in practices across sectors. 
As reported in this article, public health NGO research and knowledge mobilization activities range from publishing peer-reviewed articles, to grant writing, to program management, to the development of educational materials, to policy and advocacy work. They span activities focused on the downstream provision of treatments, services and programmatic interventions, to activities to prevent illness and promote health by changing the upstream policies and systems - the social determinants of health (WHO 2008) - in which treatments, programs, services, and communities are embedded. Findings also indicate how open access to peer-reviewed articles may affect the general dynamics of public health NGOs' research practices, fostering positive feedback loops of research and learning. These positive feedback loops may occur at staff and organizational levels, while also fostering greater awareness of the value of open access to peer-reviewed articles in new communities of stakeholders. Often such academic and professional research is synthesized with local knowledge and community-based research (Corburn, 2005). Public health NGOs thereby also contribute new insights to scholarly knowledge and professional debates. Additional research could investigate the types of knowledge infrastructures and processes that best support such organizational development and capacity-building over time, with an eye to multi-sectoral promotion of public health and health equity (WHO 2010).

On that note, intertwined with recognizing public health NGOs as key stakeholders in research and knowledge ecosystems, this paper argues for leveraging community informatics initiatives on behalf of health equity. Most of all, the rationale for considering initiatives from the vantage of health equity is to examine how public health knowledge ecosystems are oriented toward health promotion for all - or not; it is to emphasize the why, not only the how, of research and knowledge mobilization. It is crucial to observe, for instance, which community informatics initiatives are oriented toward "confronting the root causes of health inequity" [CH-184], as one participant put it, including through extending public health lenses to upstream domains of political and economic decision-making (Frumkin 2005; Corburn 2009).

Community informatics and open access initiatives are not panaceas, nor can they provide solutions to the deep social inequalities and institutional failures that translate into health inequities, as analyzed by social epidemiologists (Krieger 2011). As another open access analyst writes, "The system of scholarly communication is a complex environment made up of various stakeholders... [which] exert some degree of power upon all other groups while at the same time being influenced, directly or indirectly, by external forces" (Reinsfelder 2012). Initiatives can aid efforts by public health NGOs to promote health for all, as illustrated by some of the activities reported in this paper; but they will tend to mirror unequal social playing fields, rather than to level them.

Yet, given the prevalence and popularity of technological interventions with some funders, especially interventions emphasizing new information technologies, community informatics initiatives could better ally with health equity agendas by continually highlighting inequalities of power of many kinds (economic, social, political, cultural). Doing so would help to situate ICTs and academic research in broader problem-solving landscapes on behalf of social justice - to put them in perspective. In the case of public health NGOs, it is especially relevant to consider 
community informatics in the context of social justice movements, particularly those that challenge socio-economic inequalities and structural racism - since these are core social determinants of health, which impinge on public health NGOs' work. As Jonathan Smucker writes, "In the case of economic inequality, we could certainly use a few more left-leaning economists, but, much more so, we need to construct a broadbased political alignment..." (Smucker 2017). In other words, not only new knowledge, but new social relations, attuned to reconfiguring multiple forms of power, are needed to advance health equity. Health equity touchstones are consistent with the social justice aspirations of many who are engaged with NGO work and community informatics projects. So there is a particular opportunity to consider how to better leverage these fields, as highlighted previously in this journal (Newman and Alsanousi 2013).

So even as open access policies and journals proliferate, in some ways disrupting corporate journal publishing markets, it is crucial to recognize their limitations in a world where publishing markets are themselves embedded in multiple other corporatedominated, neoliberal markets that impact health (Holzmeyer 2018). Moreover, even within their domain, open access publishing options often maintain financial hierarchies by passing on their publishing costs to authors, who may not have funds to cover them as some public health NGO staff in this study pointed out. Indeed, the Sci-Hub platform (https://en.wikipedia.org/wiki/Sci-Hub), which has drawn many publishers' ire by allowing users to bypass paywalls through educational institution proxies, both states its support for the open access movement and operates outside-the-box of most open access initiatives. Rather than instituting new payment schemes, for example, Sci-Hub instead disregards the paywalled status of articles entirely - a more fundamental challenge to corporate journal publishing markets. Created by Kazakhstani graduate student Alexandra Elbakyan in 2011, to date Sci-Hub has stored tens of millions of papers in its own repository.

Additional allies in leveraging community informatics for health equity may include those calling for more communal and cooperative forms of social organization to accompany information sharing platforms, such as advocates of platform cooperativism (Scholz 2016) and of community data commons (Bloom 2013). All of these efforts are relevant to institutionalizing, at multiple levels and scales, supports for grassroots, community-based innovations on behalf of health equity. As a recent report from the U.S. Institute of Medicine frames work toward health equity, "The major health problems of our time, especially as related to fairness and equity in health and wellbeing, cannot be solved by health care alone. They cannot be solved by public health alone. All of our nation's institutions, public, private, and nonprofit, have important roles to play even if they do not think of their purpose as fundamentally being about health and well-being" (Marks et al. 2018). Such multi-level, multi-sectoral initiatives are needed to promote health equity and to support the work of public health NGOs as stakeholders in open access knowledge ecosystems - especially, NGOs representing the least enfranchised communities and defining their missions around social and environmental justice. 


\section{Acknowledgements}

Most of all, the author is grateful to participants for sharing their time and experiences, as well as to John Willinsky, Khosla Family Professor at the Stanford Graduate School of Education, for his postdoctoral mentorship throughout this research, and to Laura Moorhead and Lauren Maggio for their contributions to the larger study. In addition, the author thanks the following colleagues for their helpful discussions and comments on earlier iterations of this research: Lisa Börjesson, Michael Buckland, Alina Engelman, Alastair Iles, Akos Kokai, Jean Lave, Ellen Moore, Silvio Carvalho Neto, Vivien Petras, Rodrigo Ribeiro, Janaki Srinivasan and Lee Worden. This research was funded by the U.S. National Science Foundation's Science of Science \& Innovation Policy program (Grant \#1158673).

Competing interests: None.

Ethics approval: Stanford University Institutional Review Board.

\section{References}

American Public Health Association on Health Equity: https://www.apha.org/topics-and-issues/ health-equity .

Bayer, R. and Galea, S. (2015). Public Health in the Precision-Medicine Era. The New England Journal of Medicine 373:499-501.

Biebel, K., Maciolek, S., Nicholson, J., Debordes-Jackson, G. and Leslie, L. (2013). Intermediaries Promote the Use of Research Evidence in Children's Behavioral Health Systems Change. University of Massachusetts Medical School, Psychiatry Issue Brief $10(4)$.

Bloom, G. (2013). Towards a Community Data Commons. Goldstein, B. and Dyson, D., Eds., Beyond Transparency: Open Data and the Future of Civic Innovation (255-270). San Francisco, CA: Code for America Press.

Brown, P. (2005). Who is the Community/What is the Community? Brown University, Collaborative Initiative for Research Ethics: https://www.brown.edu/research/researchethics/who-communitywhat-community.

Brown, P., Morello-F Brown rosch, R., and Zavestoski, S., Eds. (2012). Contested Illnesses: Citizens, Science, and Health Social Movements. Berkeley, CA: University of California Press.

Corburn, J. (2005). Street Science: Community Knowledge and Environmental Health Justice. Cambridge, MA: The MIT Press.

Corburn (2009) Toward the Healthy City: People, Places, and the Politics of Urban Planning. Cambridge, MA: The MIT Press.

Eaves, D. (2014). Building Power Through Data-Sharing: Issues and Opportunities for Environmental Health and Justice Funders. https://hefn.org/sites/default/files/ uploaded files/eaves_paper_for_publication 8-5-14_0.pdf. 
Frumkin, H. (2005). Health, Equity, and the Built Environment. Environmental Health Perspectives 113(5): A290-A291.

Gold, M. (2009). Pathways to the Use of Health Services Research in Policy. Health Services Research 44(4): 1111-1136.

Gurstein, M. (2003). Effective use: A community informatics strategy beyond the Digital Divide. First Monday 8(12).

Gurstein, M. (2004). Editorial: Welcome to the Journal of Community Informatics. The Journal of Community Informatics 1(1): 2-4.

Gurstein, M. (2013). Community Innovation and Community Informatics. The Journal of Community Informatics 9(3).

Healthy People 2020: https://www.healthypeople.gov/2020/About-Healthy-People.

Hillery, G. (1955). Definitions of Community: Areas of Agreement. Rural Society 20: 111-125.

Holzmeyer, C. (2018) Open Science Initiatives: Challenges for Public Health Promotion. Health Promotion International, day002: https://doi.org/10.1093/heapro/day002.

Krieger, N. (2011). Epidemiology and the People's Health: Theory and Context. Oxford University Press, Oxford.

Marks, J., Gayle, H., and Proctor, D. (2018). Introduction: Social and Structural Determinants of Health and Health Equity. Perspectives on Health Equity \& Social Determinants of Health. Washington, DC: The National Academy of Medicine.

Moorhead, L.1, Holzmeyer, C.1, Maggio, L., Steinberg, R., and Willinsky, J. (2015). In an Age of Open Access to Research Policies: Physicians and Public Health NGO Staff Research Use and Policy Awareness. PLOS One, July 2015: 1-15.

Newman, L. and Alsanousi, A. (2013). Overview of ICTs and Health. The Journal of Community Informatics $9(2)$.

Nkechi, N. and Gurstein, M. (2007). Towards Supporting Community Information Seeking and Use. The Journal of Community Informatics 3(1).

Patrick, D. and Wickizer, T. (1995). Community and Health. in Amick, B., Levine, S., and Tarlov, A., and Chapman Walsh, D., Eds., Society and Health (46-92). New York: Oxford University Press.

Reinsfelder, T. (2012). Open Access Publishing Practices in a Complex Environment: Conditions, Barriers, and Bases of Power. Journal of Librarianship and Scholarly Communication 1(1), eP1029: 1.

Scholz, T. (2016). Platform Cooperativism: Challenging the Corporate Sharing Economy. New York: Rosa Luxemburg Stiftung.

Smucker, J. (2017). Hegemony How-To: A Roadmap for Radicals. AK Press, Chico, CA.

Stoecker, R. (2005). Is Community Informatics good for communities? Questions confronting an emerging field. The Journal of Community Informatics 1(3).

World Health Organization (WHO), Commission on Social Determinants of Health (2008). Closing the gap in a generation: health equity through action on the social determinants of health. Geneva: WHO.

World Health Organization (2010). Adelaide statement on Health in All Policies. Adelaide: WHO, Government of South Australia,. 